\title{
Desafios da Robótica Educacional Acessível e Inclusiva no Brasil
}

\author{
Esteic Janaina Santos Batista ${ }^{1}$, Amaury Antônio de Castro Júnior ${ }^{2}$ \\ Campus Ponta Porã - Instituto Federal de Educação, Ciência e Tecnologia \\ de Mato Grosso do Sul (IFMS) \\ Rodovia BR-463, km 14, s/nº - CEP: 79909-000 - Ponta Porã - MS - Brasil \\ ${ }^{2}$ Faculdade de Computação - Universidade Federal de Mato Grosso do Sul (UFMS) \\ Cidade Universitária - 79.070-900 - Campo Grande - MS - Brasil \\ esteic.batista@ifms.edu.br, amaury.junior@ufms.br
}

\begin{abstract}
This abstract presents the challenge of developing programming and robotics tools with publicly accessible interfaces for children and young people with special needs. These tools promote the development of skills required for the professions of the future.
\end{abstract}

Resumo. Este resumo apresenta o desafio de desenvolvimento de ferramentas de programação e robótica com interfaces acessíveis ao público de crianças e jovens com necessidades especiais. Estas ferramentas promovem o desenvolvimento de competências requeridas para as profissões do futuro.

\section{Motivação e Considerações Iniciais}

O ensino de programação e robótica para crianças e jovens já é uma realidade em muitas regiões do país e do mundo. O estudante desenvolve a capacidade crítica, melhora o raciocínio lógico, busca novas soluções frente aos problemas com os quais se depara ao longo de sua vida, além de desenvolver o Pensamento Computacional, uma competência necessária para as profissões do futuro.

Segundo o censo escolar de 2018, realizado pelo Instituto Nacional de Estudos e Pesquisas Educacionais Anísio Teixeira (Inep), na educação básica, houve um aumento $33 \%$ de matrículas na educação especial em escolas públicas de todo país, nos últimos quatro anos ${ }^{1}$. Entretanto, no Brasil, ainda existem poucas discussões em relação à pesquisa, produção e desenvolvimento de ferramentas, interfaces e materiais pedagógicos para o ensino de programação e robótica acessíveis. Também são reduzidos os relatos de experiência e aplicação de tais ferramentas junto ao público de estudantes com necessidades especiais, visando à inclusão em projetos escolares que usem a robótica para o desenvolvimento de competências e habilidades relacionadas.

Em sua sua abordagem construcionista, Papert desenvolveu a linguagem Logo, de fácil compreensão e manipulação por crianças ou por pessoas leigas em computação e sem domínio da matemática. Em sua pesquisa, Papert chamou de micromundos os ambientes de aprendizagem onde é possível explorar, descobrir e simular acontecimentos da vida real [Papert 1994].

\footnotetext{
${ }^{1}$ Disponível em: http://portal.inep.gov.br/web/guest/resultados-e-resumos. Acesso: 18/08/2019
} 
Em 2009, foi criado o Scratch, uma ferramenta de ensino de programação para crianças, similar no Logo. O Scratch foi resultado do trabalho da equipe do pesquisador Mitchel Resnick, que em um trabalho recente, apresenta a Teoria dos 4Ps [Resnick 2014] da aprendizagem criativa, que estão fortemente inspirados e alinhados com a abordagem construcionista da educação, que enfatiza a criação de soluções e projetos, que sejam pessoalmente significativos, de forma lúdica e colaborativa.

Posteriormente, outros ambientes e ferramentas de programação visual em blocos surgem, como o ScratchJr, destinados para crianças mais novas e sem domínio da leitura; o AppInventor, que permite criar aplicativos móveis de forma lúdica; e as ferramentas do Code.Org, que contêm cursos e atividades para ensino de programação para todos as idades. Além destas, existem diversas outras ferramentas para programação de robôs de kits específicos de robótica e eletrônica.

Em 2017, o trabalho de Batista apresentou uma análise das interfaces de ferramentas de programação mais populares para o ensino de crianças [Batista 2017]. Observou-se que, apesar da grande utilidade das ferramentas analisadas, nenhuma delas mostrou-se acessível a crianças com necessidades especiais .

No Brasil, existem ações de uso da robótica para crianças com necessidades especiais em que as mesmas atuam como protagonistas e autoras da criação destas tecnologias. No trabalho de [Lopes et al. 2015], foi ofertado um curso de robótica para sessenta e quatro crianças e adolescentes, sendo quatro surdos, um esquizofrênico, um com síndrome de Asperger e um com dificuldade de aprendizagem. No entanto, o relato do seu trabalho menciona que as aulas tornaram-se acessíveis a este público em razão da participação de um profissional intérprete de Libras nas aulas e de profissionais de psicologia no auxílio da preparação do curso.

Já no trabalho de [Barros 2017], são propostas tecnologias educacionais assistivas a fim de possibilitar o uso da robótica educacional junto a pessoas com deficiência visual ou baixa visão, através de uma proposta alternativa de programação tátil com cartões de papel. Estes cartões têm formatos distintos para que o estudantes com deficiência visual possam distinguir as ações do robô. Cada cartão contém um QR Code que é decodificado, através do aplicativo CardBot, proposto no trabalho, que visa controlar e programar qualquer hardware de robótica educacional à distancia.

Recentemente, a Microsoft desenvolveu uma linguagem de programação física, intitulada Code Jumper, para tornar a codificação acessível a qualquer pessoa com deficiência visual ${ }^{2}$. O Code Jumper permite que os usuários conectem blocos coloridos para acionar diferentes comandos e construir programas que possam contar histórias, fazer música e até mesmo contar piadas.

As iniciativas apresentadas acima são válidas e importantes. No entanto, quando comparadas ao grande número de crianças com necessidades especiais, ainda são poucas, principalmente com deficiência visual no Brasil e no crescente uso da robótica pedagógica nas escolas brasileiras. Portanto, o desenvolvimento de materiais e ferramentas com interfaces acessíveis que utilizem de diferentes mecanismos, como a programação tátil para deficientes visuais, tornam-se necessárias e desafiadoras, para que as habilidades desen-

\footnotetext{
${ }^{2}$ Disponível em: https://www.thiagosaccol.com.br/conteudo/microsoft-code-jumper-um-brinquedoque-ensina-criancas-com-deficiencia-visual-a-programar/. Acesso em: 18/8/2019
} 
VIII Congresso Brasileiro de Informática na Educação (CBIE 2019)

Anais do VIII Workshop de Desafios da Computação aplicada à Educação (DesafIE 2019)

volvidas com a programação e robótica pedagógica, estejam disponíveis para todos.

\section{Referências}

Barros, R. P. (2017). CardBot: tecnologia educacional assistiva para inclusão de deficientes visuais na robótica educacional. PhD thesis, UFRN.

Batista, E. J. S. (2017). Uma Análise de Ambientes de Programação em Blocos com Base em Recomendações de Interação Criança-Computador. Trabalho de Conclusão de Curso - UFMS.

Lopes, L., dos Santos, L. M. M., de Souza, L. F. F., Barroso, M. F. S., da Silva, C. V., Serpa, B. R., and Pereira, E. B. (2015). A robótica educacional como ferramenta multidisciplinar: um estudo de caso para a formação e inclusão de pessoas com deficiência. Revista Educação Especial, 28(53):735-749.

Papert, S. (1994). A máquina das crianças. Porto Alegre: Artmed.

Resnick, M. (2014). Give p's a chance: Projects, peers, passion, play. In Constructionism and creativity: Proceedings of the Third International Constructionism Conference. Austrian Computer Society, Vienna, pages 13-20. 